\title{
THE IMPACT OF SOCIAL MEDIA USE AND CONTENT ON THE YOUNGER GENERATION'S MENTAL HEALTH IN INDONESIA
}

\author{
Selina Maurizka, Putu Wuri Handayani and Widia Resti Fitriani \\ Faculty of Computer Science, University of Indonesia \\ Depok, Indonesia
}

\begin{abstract}
This study aims to analyse the impact of social media use and content on the mental health of young people in Indonesia. This research uses a quantitative approach using an online questionnaire. There were 1,402 respondents who participated in this study. The collected data was analysed using a multiple linear regression method with a mediation relationship. The tool used to process the data was IBM SPSS version 25. This research shows that social media use, social media content, emotion regulation, perceived stress, and poor sleep affects depressive symptoms. The results of this study can help regulators and health service providers to provide better facilities for handling mental health cases, especially those due to the use and content of social media. The results of this study are expected to help social media developers develop features that provide a safe online environment for social media users.
\end{abstract}

\section{KEYWORDS}

Mental Health, Social Media, Social Media Use, Social Media Content, Young Generation, Indonesia

\section{INTRODUCTION}

Social media is now very knitted into the daily lives of most people. According to Clement (2020b), social media users will continue to increase, and the number is projected to be almost 3.43 billion in 2023 . Indonesia ranks fourth highest in the world for Internet users (Clement, 2020a). Based on the results of a survey conducted by the Indonesian Internet Service Providers Association (APJII), the number of Internet users in Indonesia has reached $64.8 \%$ of the total population of Indonesia (APJII, 2018). APJII (2018) also found that the social media frequently visited by Indonesian residents were Facebook at 50.7\%, Instagram at $17.8 \%$, and YouTube at 15.1\%. According to Kemp (2019), active social media users in Indonesia in 2019 numbered 150 million people, up $15 \%$ to $20 \%$ from 2018.

Mental health is a serious issue in Indonesia; the prevalence of severe mental disorders in Indonesia's population is $1.7 \%$ (Hartini et al., 2018). In addition, based on data from the Ministry of Health of the Republic of Indonesia, it is estimated that in $2018,6.1 \%$ of the population aged 15 years and older had experienced depression. Social media users in children and adolescents number approximately 30 million people in Indonesia, according to the Ministry of Communication and Information, and the level of Internet addiction among teenagers in Jakarta has reached 31.4\%, far surpassing the world's levels of 4.5-19.1\% and levels in young adults of around $0.7-18.3 \%$ (Napitupulu, 2019). According to the National Information and Communication Technology Board, during the COVID-19 pandemic, the use of the Instagram application rose $40 \%$ because many people used social media to communicate during quarantine. Based on these problems, an understanding of the impact of the use of social media and content on social media is needed, especially since Indonesia is currently experiencing a significant increase in the number of young people.

Although there is a correlation between the use of social media and mental health, the relationship between them is still considered unclear (de Calheiros Velozo \& Stauder, 2018; Rasmussen et al., 2020). Moreover, the use of social media might be associated with negative mental health, such as suicide, loneliness, and lack of empathy (Berryman et al., 2018). In addition, Shensa et al. (2020) found that social media use is associated with depressive symptoms. Stress is also one of the factors associated with the use of 
social media (Rasmussen et al., 2020). Emotion and stress regulation is ultimately related to producing a higher likelihood of some mental disorders (Aldao et al., 2010). The use of social media is also often associated with the quality of one's sleep (Woods \& Scott, 2016). Levenson et al. (2016) also found that the use of social media is associated with disruption of one's sleep time, including difficulties getting to sleep and poor quality of sleep. Further, Thompson and Lougheed (2012) found that social media users, especially young people, spend as much as $54 \%$ of their time accessing social media.

To date, there is not much research that addresses the effects of social media content on mental health. Coyne et al. (2020) found no influence of time spent on using social media on mental health. In addition, de Calheiros Velozo, and Stauder (2018) found that there was no relationship between viewing a person's content and emotional symptoms. In addition, there has been no research related to the relationship between social media content, poor sleep, perceived stress, and emotion regulation on the mental health of young people in Indonesia. Thus, this study aims to better understand the impact of social media use and social media content that can affect the mental health of the younger generations. This research is expected to benefit social media users, social media developers, and health workers by informing them about the impact of social media on mental health.

\section{METHODS}

\subsection{Conceptual Model \& Research Hypothesis}

Social media use is an important element in the development of adolescents and young people because they can interact with others and present in creating their online identity (Bartsch et al., 2015). In general, social media use is associated with higher levels of anxiety and depression (Banjanin et al., 2015; Pantic et al., 2012; Woods \& Scott, 2016). Research shows that there is a relationship between the time spent using social media and feelings of depression and anxiety in adolescents (Banjanin et al., 2015; Barry et al., 2017; Pantic et al., 2012; Woods \& Scott, 2016). Further, Sujarwoto et al. (2019) found an influence between the use of social media and mental health in developing countries, such as in Indonesia.

Hormes et al. (2014) found that high social media use causes difficulties in emotion regulation. Emotion regulation is awareness, clarity, acceptance, access, ability to control, and ability to response through emotional responses (Gratz et al., 2004). Emotional regulation is considered important because excessive use of social media can cause depression, especially for people in developing countries, such as in Indonesia (Sujarwoto et al., 2019). In addition, Zahniser and Conley (2018) have shown that difficulties with emotion regulation are associated with indicators of stress or perceived stress in emerging adults.

Akin and İskender (2011) found an association between addictive Internet use with depression, anxiety, and stress. Young people in early adulthood experience extreme anxiety when their access to text messages is restricted and report feelings of stress and guilt when they do not immediately respond to messages (Thomée et al., 2010). Rasmussen et al. (2020) found that feelings of stress are related to problems with mental health. Having a good ability to self-regulate signifies the ability to remain calm in stressful situations or to withstand feelings of anger and frustration (de Calheiros Velozo \& Stauder, 2018).

An et al. (2014) found a relationship between social media use and sleep disturbance. Social media is generally associated with poor sleep outcomes, specifically shorter sleep duration, delayed sleep time, and poor sleep quality (Levenson et al., 2016). Poor sleep quality is known to contribute to feelings of anxiety, depression, and low self-esteem in adolescents (Alfano et al., 2009). Research conducted by Nursalam et al. (2019) of Indonesian teenagers proved that the duration of use of social media affects the quality of sleep, which can cause insomnia. Problems with sleep quality can contribute to psychological problems such as depression (Eipstein, 2008).

H1. Social media use (SMU) influences depressive symptoms (DS)

H2. Social media use (SMU) influences emotion regulation (ER) which will influence depressive symptoms $(D S)$

H3. Social media use (SMU) influences perceived stress (PS) which will influence depressive symptoms $(D S)$ 
H4. Social media use (SMU) influences emotion regulation (ER) which will influence perceived stress $(P S)$, and in the end will influence depressive symptoms (DS)

H5. Social media use (SMU) influences poor sleep (PSL) which will influence depressive symptoms (DS)

H6. Social media use (SMU) influences poor sleep (PSL), which will influence perceived stress (PS), and in the end will influence also depressive symptoms $(D S)$

Content is basically anything that touches or interacts with a targeted prospect, including online properties and everything on social media (Handley, 2014). Research by Viner et al. (2019) found that activities, such as watching dangerous content, could have direct harmful effects on mental health. One way that this can cause a negative impact on mental health relates to a person's inability to prove a trait or activity that is considered cool and the effort required to remain part of an online group (Mcdool et al., 2016). Exposure to various forms of media can be an effective means of manipulating a person's emotional mood (Zillmann, 2000), but an individual is not necessarily aware of how they use the media to regulate the state of their mood (Holger \& Werner, 2008).

According to research by Rideout and Fox (2018), seeing too much negative news can make a person feel stressed and anxious. Thomée et al. (2010) found that stress can come from a never-ending flood of information that comes in the form of messages, emails, updates, etc. According to Rasmussen et al. (2020), stress plays a direct role in mental health problems. Awareness about stress events uploaded by others may also negatively affect someone's mental health, because through social media, users will be more aware of the struggles of the people in their network (Hampton et al., 2019).

Moreover, sleep disturbance due to notifications from social media content is one of the possible causes of the relationship between social media and poor sleep quality (Woods \& Scott, 2016). Social media content on Instagram, Facebook, or Twitter can limit a person's sleep hours because they are compelled to check the content on an ongoing basis (Linetti, 2019). According to Harususilo (2018), some teenagers in Indonesia try so hard to maintain their existence on social media that it makes them lose sleep at night while they choose the best content to upload on Instagram; this can adversely affect teenagers. Harususilo (2018) shows that adolescents need 9.5 hours of sleep each night but only get 7.5 hours; the impact of this lack of sleep can make children tired, irritable, stressed, and prone to sickness.

H7. Social media content (SMC) influences depressive symptoms (DS)

H8. Social media content (SMC) influences emotion regulation (ER) which will influence depressive symptoms $(D S)$

H9. Social media content (SMC) influences perceived stress (PS) which will influence depressive symptoms $(D S)$

H10. Social media content (SMC) influences poor sleep (PSL) which will influence depressive symptoms $(D S)$

H11. Social media content (SMC) influences emotion regulation (ER) which will influence perceived stress (PS), and in the end will influence depressive symptoms (DS)

H12. Social media content (SMC) influences poor sleep (PSL) which will perceived stress (PS), and in the end will influence depressive symptoms (DS)

\subsection{Research Instruments}

This study divides the questionnaire into two parts, namely the demographic information and the statements related to the research, which involved 34 questions. The demographic section consists of respondents' gender, age, occupation, education, domicile of residence, use of social media, use of social media features, types of social media information that are frequently searched for, types of information that create stress, and sources of information that create stress. All sections except questions for depressive symptoms and one statement on poor sleep use a Likert scale of 1 to 5, starting from one that shows strongly disagree to five that shows strongly agree. The depressive symptoms section of respondents answered using a Likert scale from 1 to 3 and one question on the poor sleep section used a Likert scale from 1 to 4 . A Likert scale of 3 has the correct, sometimes, and incorrect options. Likert scale of 4 adjusted to the context of the question where each scale will contain a time range. 


\subsection{Data Collection \& Analysis}

The questionnaire took approximately 10 minutes to complete and all respondents' answers were given anonymously. All respondents gave informed consent to fill out the questionnaires, which was followed by the questionnaire link being distributed through social media platforms such as Twitter, Facebook, Instagram, or dan LINE. Social media were chosen because they have the highest number of users in Indonesia. According to Müller (2019b), in 2018, social media users in Indonesia numbered 81 million people. Because of this high number, we set the target respondents for this study as young people who have used social media. The data processing method used was mediation relationship with multiple linear regression. The tools used to help process the data were IBM SPSS version 25 and, for processing data, an add-on in SPSS consisting of PROCESS macros created by Andrew F. Hayes.

\section{RESULTS}

The research questionnaire was distributed over three weeks online starting from February 20, 2020 to March 13, 2020 (23 days). We successfully obtained 1,402 complete questionnaires after we deleted invalid data. This research has fulfilled the requirements of the assumption test, namely multicollinearity test, homoscedasticity test and linearity test, independence test, and normality test (Hayes, 2018; Lund, 2018). Hypotheses 1 and 7 used a linear regression test without mediation. The hypothesis with one mediating variable has three direct effect relationships. Furthermore, the hypothesis with two mediating variables has six direct effect relationships. Indirect effect serves to describe the path effect from the independent variable to the dependent variable through mediating variables (Hayes, 2018). The results of the indirect effect can illustrate whether the effect of the independent variable on the dependent variable is transmitted through the mechanism represented by the causal chain of events (Hayes, 2018). Hypothesis testing is done in two directions (two-tailed). There are 12 accepted hypotheses that have p-values below 0.05 and $t$ values greater than 1.96, and also for hypothesis with indirect effects can be accepted if the Effect value is between BootLLCI and BootULCI, which can be seen at Table 1.

Table 1. Indirect Effects

\begin{tabular}{llll}
\hline Relationship & Effect & BootLLCI & BootULCI \\
\hline SMU -> ER -> DS & 0,2736 & 0,2041 & 0,3558 \\
SMU -> PS -> DS & 0,0693 & 0,0153 & 0,1027 \\
SMU -> ER -> PS -> DS & 0,0622 & 0,042 & 0,0858 \\
SMU -> PSL -> DS & 0,0164 & 0,0049 & 0,032 \\
SMU -> PSL -> PS -> DS & 0,0238 & 0,0081 & 0,0409 \\
SMC -> ER -> DS & $-0,1883$ & $-0,2284$ & $-0,149$ \\
SMC -> PS -> DS & $-0,054$ & $-0,074$ & $-0,0354$ \\
SMC -> PSL -> DS & $-0,0091$ & $-0,0174$ & $-0,0029$ \\
SMC -> ER -> PS -> DS & $-0,0427$ & $-0,057$ & $-0,0298$ \\
SMC -> PSL -> PS -> DS & $-0,013$ & $-0,0219$ & $-0,0052$ \\
\hline
\end{tabular}

\section{DISCUSSION}

This study found that social media use has an influence on depressive symptoms (H1). This supports research by Banjanin et al. (2015), Barry et al. (2017), Pantic et al. (2012), and Woods and Scott (2016), which states that the time of use of social media has an influence on feelings of depression and anxiety. The use of social media on an ongoing basis is often blamed for causing problems with mental health, especially in young people and adolescents (Charles, 2019). In developing countries, increased use of social media, such as Facebook and Twitter, not only offers benefits, allowing individuals to connect with others, but can also have harmful effects on their mental health (Sujarwoto et al., 2019). The use of social media in Indonesia can negatively affect how users see the world, due to the high prevalence of negative news that is spread through social media (Müller, 2020). 
Social media use also influences emotion regulation and affects depressive symptoms (H2). These results support previous research that emotion regulation plays a mediating role between the use of social media and mental health (Rasmussen et al., 2020). A high level of social media use is an example of engagement with an addictive activity, which suggests a lack of ability to regulate oneself (Lu et al., 2016). Further, Hormes et al.'s (2014) state that social media use causes difficulties for some people to regulate their emotions. Spending a lot of time on social media reduces self-control because users may start copying new behaviours from friends on social media (Linetti, 2019). According to Ministry of Communication and Information, with the increasing development of social media for use by young people in Indonesia, parents need to be stricter about the use of social media for their children. A duration of Internet and social media usage of more than 20 hours per week (Napitupulu, 2019) indicates that there is poor regulation of behaviour in relation to social media; if this pattern continues, it can have a negative impact on the person's mental health.

Furthermore, social media use has an influence on perceived stress and affects depressive symptoms (H3). These results support research by Akin and İskender (2011), which states that addictive use of the Internet is associated with depression, anxiety, and stress. Another cause of stress is the consciousness of the need to stop using social media, but which they have failed at, causing a person to feel more stress (Linetti, 2019). According to the 2018 Basic Health Research study conducted by the Ministry of Health, the number of Indonesian citizens who experience depression that leads to suicide is $6.1 \%$, which is equivalent to 11 million people; this figure is for citizens over the age of 15 years.

In addition, social media influences emotion regulation and perceived stress, which affects depressive symptoms (H4). This supports previous research conducted by Rasmussen et al. (2020), which states that the ability of someone who uses social media to regulate their emotions affects the stress they face, which ultimately affects their mental health. Our analysis found that when comparing emotional and stress regulation pathways, emotional regulation pathways had a more significant influence than stress pathways. De Calheiros Velozo and Stauder (2018) state that a person's emotional regulation influences feelings of stress; for example, someone who has a good ability to self-regulate tends to have the ability to remain calm in stressful situations.

Social media use has an influence on poor sleep, which affects depressive symptoms (H5). These results support Woods and Scott (2016) research that found a significant relationship between the use of social media at night and poor sleep quality, which can cause feelings of anxiety and depression. This relates to studies by the University of Pittsburgh showing that the more time spent by young people on social media, the more likely they are to experience problems with sleep and show symptoms of depression (Levenson et al., 2016). According to Harvard Medical School (2019), one of the psychological effects of sleep deprivation is depression. In Indonesia, use of social media that exceeds 5 hours is associated with insomnia, which can cause mental health problems (Nursalam et al., 2019).

The fact that social media use has an influence on poor sleep and perceived stress affects depressive symptoms (H6). According to Levenson et al. (2016), people may have difficulty sleeping as a result of spending more time using social media; however, people with pre-existing sleep conditions can also use social media as a fun way to spend time when awake or to divert themselves from their difficulty of getting to sleep. According to Harvard Medical School (2019), problems with sleep are related to anxiety, depression, bipolar disorder, and attention deficit hyperactivity disorder (ADHD).

Furthermore, social media content has an influence on depressive symptoms (H7). Existing content on social media, such as harmful content (i.e. pornography, etc.), can affect one's mental health (Viner et al., 2019). According to Müller (2019a), false news that spreads online has a negative impact on Indonesians. Based on a survey conducted by Statista in 2019 in Indonesia, 58.3\% of respondents said they read the latest news on social media (Müller, 2019a). Content that spreads on social media can also have a negative impact on the mental health of users (Hogenboom, 2018). Sujarwoto et al. (2019) found that news that spreads on social media contains mostly negative content, such as crime, corruption, and so on; news like that can make readers feel depressed.

Social media content influences emotion regulation and affects depressive symptoms (H8). This supports previous research that shows that people who are more selective of media content, using it to meet different needs, have a higher level of emotional regulation, which influences their ability to choose the content that is right for them (Schramm \& Cohen, 2017). Content viewed by social media users can be an effective way to manipulate their emotional mood (Zillmann, 2000). Sukmayadi and Effendi (2018) found that many respondents of social media users felt frustrated and exhausted from the content and tone of the political environment in their social media timeline. 
Furthermore, social media content has an influence on perceived stress and affects depressive symptoms (H9). This supports research conducted by Rideout and Fox (2018), which states that seeing too much negative content can make a person feel stressed and anxious. Thomée et al. (2010) says that stress arises when people view photo uploads, when they feel the need to follow uploads continuously via Twitter, or when they view activities that make them feel left behind by their friends. This result also supports research by Hampton et al. (2019) that shows someone's mental health can be affected by events uploaded by others in their network.

Next, social media content has an influence on poor sleep and affects depressive symptoms (H10). This supports previous research by Woods and Scott (2016) that social media, including notifications or content, is the cause of poor sleep quality. The results of this analysis test support the statement of Linetti (2019) that social media content on Instagram, Facebook, or Twitter can reduce people's sleep time, making their sleep quality worse. According to research by Nursalam et al. (2019), social media can make adolescents in Indonesia experience insomnia, while according to Alvaro et al. (2014), insomnia can have an impact on a person's psychology, causing issues such as depression, anxiety, withdrawal symptoms from addiction, and aggression.

The next result is that social media content has an influence on emotion regulation and perceived stress, which affects depressive symptoms (H11). Research from the UCLA Brain Mapping Center found that the number of 'likes' in a photo creates higher activity in the brain, so teenagers are more likely to give 'likes' to a photo regardless of the content, as they only care about the number of 'likes' (Sherman et al., 2016). The ability to regulate emotions can impact the existence of stressful feelings, as shown by the results of research by Zahniser and Conley (2018). Someone who can regulate emotions can regulate their affective circumstances, thereby reducing negative feelings and maintaining a positive mood (Zillmann, 2000). However, with the rapidly growing use of social media among young people, parental support and digital media integration are still lagging; therefore, efforts are needed to raise awareness for all groups.

Finally, social media content has an influence on poor sleep and perceived stress, which affects depressive symptoms (H12). The results of this analysis support research by Woods and Scott (2016) showing that a person can have poor sleep quality due to social media content or notifications that appear, which will lead to poor sleep that can trigger stress, which then has physiological and psychological consequences (Walker \& Stickgold, 2006). High levels of adolescent addiction in Indonesia on social media among adolescents (Napitupulu, 2019) will have an impact on sleep duration and poor sleep quality. High levels of social media usage can cause anxiety, depression, and suicide for young people (McBride, 2011).

\section{CONCLUSION}

The results of the data analysis found that social media use can affect depressive symptoms through several channels, namely through emotion regulation, poor sleep, perceived stress, emotion regulation and perceived stress, and poor sleep and perceived stress. Further, social media content can affect depressive symptoms through emotion regulation, poor sleep, perceived stress, emotion regulation and perceived stress, as well as poor sleep and perceived stress. There needs to be a higher level of awareness and real action in developing social media applications to reduce the number of mental health patients. Social media users should also be more careful in using social media because excessive use can cause mental health problems. Future studies are expected to develop more specific social media content contexts.

\section{REFERENCES}

Akin A. et al, 2011. Internet addiction and depression, anxiety and stress. International Online Journal of Educational Sciences, 3(1), pp 138-148.

Aldao A. et al, 2010. Emotion-regulation strategies across psychopathology: A meta-analytic review. Clinical Psychology Review, 30(2), pp 217-237.

Alfano C. et al, 2009. Sleep problems and their relation to cognitive factors, anxiety, and depressive symptoms in children and adolescents. Depression and Anxiety, 26(6), pp 503-512. 
Alvaro P. et al, 2014. The independent relationships between insomnia, depression, subtypes of anxiety, and chronotype during adolescence. Sleep Medicine, 15(8), pp 934-941.

An J. et al, 2014. Associations between problematic Internet use and adolescents' physical and psychological symptoms: Possible role of sleep quality. Journal of Addiction Medicine, 8(4), pp 282-287.

Asosiasi Penyelenggara Jasa Internet Indonesia [APJII], 2018. Penetrasi dan Perilaku Profil Pengguna Internet Indonesia. Jakarta: Asosiasi Penyelenggara Jasa Internet Indonesia.

Banjanin N. et al, 2015. Relationship between Internet use and depression: Focus on physiological mood oscillations, social networking and online addictive behavior. Computers in Human Behavior, 43, pp 308-312.

Barry C. et al, 2017. Adolescent social media use and mental health from adolescent and parent perspectives. Journal of Adolescence, 61, pp 1-11.

Bartsch M. et al, 2015. Technology and Self-Presentation. In The Wiley Handbook of Psychology, Technology, and Society, pp 339-357.

Berryman C. et al, 2018. Social media use and mental health among young adults. Psychiatric Quarterly, 89, pp 307-314.

Charles S., 2019. Social media linked to rise in mental health disorders. Retrieved from https://www.nbcnews.com/health/mental-health/social-media-linked-rise-mental-health-disorders-teens-survey-findsn982526

Clement J., 2020a. Number of Internet users in selected countries 2019. Retrieved from https://www.statista.com/statistics/262966/number-of-internet-users-in-selected-countries/

Clement J., 2020b. Number of social media users worldwide 2010-2021. Retrieved from https://www.statista.com/statistics/278414/number-of-worldwide-social-network-users/

Coyne S. et al, 2020. Does time spent using social media impact mental health?: An eight year longitudinal study. Computers in Human Behavior, 104, 106160.

de Calheiros Velozo J. \& Stauder J. E. A., 2018. Exploring social media use as a composite construct to understand its relation to mental health: A pilot study on adolescents. Children and Youth Services Review, 91, 398-402.

Eipstein L. J., 2008. Sleep and mood. Retrieved from http://healthysleep.med.harvard.edu/need-sleep/whats-in-it-foryou/mood

Gratz K. L. \& Roemer L., 2004. Multidimensional Assessment of Emotion Regulation and Dysregulation: Development, Factor Structure, and Initial Validation of the Difficulties in Emotion Regulation Scale. Journal of Psychopathology and Behavioral Assessment, 26(1), pp 41-54.

Hair J. F. et al, 2019. Multivariate data analysis. Andover, Hampshire, United Kingdom: Cengage.

Hampton K. et al, 2019. Psychological stress and social media use. Retrieved from https://www.pewresearch.org/internet/2015/01/15/psychological-stress-and-social-media-use-2/

Handley A., 2014. Everybody writes: your go-to guide to creating ridiculously good content. New Jersey: John Wiley $\&$ Sons, Inc

Hartini N. et al, 2018. Stigma toward people with mental health problems in Indonesia. Psychology Research and Behavior Management, 11, pp 535-541.

Harususilo Y. E., 2018. Siswa Aktif Media Sosial Rentan Insomnia. Retrieved from https://edukasi.kompas.com/read/2018/09/19/19372001/siswa-aktif-media-sosial-rentan-insomnia-dancemas?page $=$ all

Harvard Medical School, 2019. Sleep and Mental Health. Retrieved from https://www.health.harvard.edu/newsletter_article/sleep-and-mental-health

Hayes A. F., 2018. Introduction to mediation, moderation, and conditional process analysis, second edition: A regression-based approach. The Guilford Press.

Hogenboom M., 2018. The vital time you should not be on social media. Retrieved from http://www.bbc.com/future/story/20180110-the-vital-time-you-really-shouldnt-be-on-social-media.

Holger S. \& Werner W., 2008. A case for an integrative view on affect regulation through media usage. Communications, $33(1)$, pp $27-46$.

Hormes J. et al, 2014. Craving Facebook? Behavioral addiction to online social networking and its association with emotion regulation deficits. Addiction, 109(12), 2079-2088.

Kemp S., 2019. Digital 2019: Indonesia - DataReportal - Global digital insights. Retrieved from https://datareportal.com/reports/digital-2019-indonesia

Levenson, J. et al, 2016. The association between social media use and sleep disturbance among young adults. Preventive Medicine, 85, pp 36-41.

Linetti L., 2019. Why social media is boosting your stress. Retrieved from https://www.thejakartapost.com/life/2019/01/09/why-social-media-is-boosting-your-stress.html 
Lu J. et al, 2016. Consuming, sharing, and creating content: How young students use new social media in and outside school. Computers in Human Behavior, 64, pp 55-64.

Lund A., 2018. Multiple linear regression in SPSS statistics. Retrieved from https://statistics.laerd.com/spsstutorials/multiple-regression-using-spss-statistics.php

McBride, D. L., 2011. Risks and benefits of social media for children and adolescents. Journal of Pediatric Nursing, 26(5), pp 498-499.

Mcdool E. et al (2016). Social media use and children's wellbeing: IZA discussion paper No. 10412. Retrieved from https://www.sheffield.ac.uk/polopoly_fs/1.669622!/file/paper_2016011.pdf

Ministry of Health of the Republic of Indonesia, 2018. Riset Kesehatan Dasar oleh Badan Penelitian dan Pengembangan Kesehatan Kementerian $\quad$ RI tahun $2018 . \quad$ Retrieved from http://www.depkes.go.id/resources/download/infoterkini/materi_rakorpop_20 18/Hasil\%20Riskesdas\%202018.pdf

Müller J., 2019a. Indonesia: Most popular social media content 2019. Retrieved from https://www.statista.com/statistics/1050401/indonesia-most-popular-social-media-content-2019/

Müller J., 2019b. Number of social network users in Indonesia 2023. Retrieved from https://www.statista.com/statistics/247938/number-of-social-network-users-in-indonesia/

Müller J., 2020. Indonesia: Social media penetration 2019. Retrieved from https://www.statista.com/statistics/284437/indonesia-social-network-penetration/

Napitupulu E. L., 2019. Tingkat Kecanduan Remaja Indonesia pada Internet Sangat Tinggi. Retrieved from https://kompas.id/baca/humaniora/dikbud/2019/11/19/tingkat-kecanduan-remaja-indonesia-pada-internet-sangattinggi/

Nursalam N. et al, 2019. Association between insomnia and social network site use in Indonesian adolescents. Nursing Forum, 54(2), pp 149-156.

Pantic I. et al, 2012. Association between online social networking and depression in high school students: Behavioral physiology viewpoint. Psychiatria Danubina, 24(1), pp 90-93.

Rasmussen E. E. et al, 2020. The serially mediated relationship between emerging adults' social media use and mental well-being. Computers in Human Behavior, 102, pp 206-213.

Rideout V. \& Fox S., 2018. Digital health practices, social media use, and mental well-being among teens and young adults in the U.S. San Francisco, CA: Hopelab and Well Being Trust. Available at: https://www.hopelab.org/reports/pdf/a-national-sur vey-by-hopelab-and-well-being-trust-2018.pdf.

Schramm H. \& Cohen E. L., 2017. Emotion Regulation and Coping via Media Use. The International Encyclopaedia of Media Effects, pp 1-9.

Shensa A. et al, 2020. Emotional support from social media and face-to-face relationships: Associations with depression risk among young adults. Journal of Affective Disorders, 260, pp 38-44.

Sherman L. E. et al, 2016. The power of the like in adolescence: Effects of peer influence on neural and behavioral responses to social media. Psychological Science, 27(7), pp 1027-1035.

Sujarwoto S. et al, 2019. A tool to help or harm? Online social media use and adult mental health in Indonesia. International Journal of Mental Health and Addiction, 17, pp 1076-1093.

Sukmayadi V. \& Effendi R., 2018. Social media emotion in politics: An Indonesian case study of political environment on Facebook. IOP Conference Series: Earth and Environmental Science, 145, 012009.

Thomée S. et al, 2010. Perceived connections between information and communication technology use and mental symptoms among young adults - A qualitative study. BMC Public Health, 10, pp 66.

Thompson S. H. \& Lougheed E., 2012. Frazzled by Facebook? An exploratory study of gender differences in social network communication among undergraduate men and women. College Student Journal, 46(1), pp 88-98.

Viner R. M. et al (2019). Roles of cyberbullying, sleep, and physical activity in mediating the effects of social media use on mental health and wellbeing among young people in England: a secondary analysis of longitudinal data. The Lancet Child and Adolescent Health, 3(10), pp 685-696.

Walker M. P. \& Stickgold R., 2006. Sleep, memory, and plasticity. Annual Review of Psychology, 57, pp 139-166.

Woods H. C. \& Scott H., 2016. \#Sleepyteens: Social media use in adolescence is associated with poor sleep quality, anxiety, depression and low self-esteem. Journal of Adolescence, 51, pp 41-49.

Zahniser E. \& Conley C. S., 2018. Interactions of emotion regulation and perceived stress in predicting emerging adults' subsequent internalizing symptoms. Motivation and Emotion, 42, pp 763-773.

Zillmann D., 2000. Mood management in the context of selective exposure theory. Annals of the International Communication Association, 23(1), pp 103-123. 